\title{
Discretionary food and beverage consumption and its association with demographic characteristics, weight status, and fruit and vegetable intakes in Australian adults
}

\author{
Zhixian Sui ${ }^{1, *}$, Weng Kei Wong ${ }^{1}$, Jimmy Chun Yu Louie ${ }^{1,2}$ and Anna Rangan ${ }^{1}$ \\ 'Level 4 EAST, Charles Perkins Centre (D17), The University of Sydney, Johns Hopkins Drive, Camperdown, \\ NSW 2050, Australia: ${ }^{2}$ School of Biological Sciences, Faculty of Science, The University of Hong Kong, Pokfulam, \\ Hong Kong Special Administrative Region, People's Republic of China
}

Submitted 20 April 2016: Final revision received 3 July 2016: Accepted 18 July 2016: First published online 30 August 2016

\begin{abstract}
Objective: Excessive consumption of discretionary foods/beverages in the Australian population has been identified, increasing the risk of obesity and chronic disease. The present study aimed to examine the associations between demographic, anthropometric and dietary factors and the consumption of discretionary foods, discretionary beverages and discretionary foods/beverages combined.

Design: Discretionary food/beverage consumption reported in two $24 \mathrm{~h}$ recalls was analysed, stratified by gender, age, socio-economic status, country of birth, BMI, waist circumference, and fruit and vegetable intakes.

Setting: 2011-12 National Nutrition and Physical Activity Survey.

Subjects: Australian adults ( $n$ 7873) aged 19 years or above.

Results: Mean discretionary food and beverage consumption was $631 \mathrm{~g}$ (28\% by weight from foods; $72 \%$ from beverages), providing $2721 \mathrm{~kJ}$ of energy intake ( $72 \%$ from foods; $28 \%$ from beverages). Total discretionary food/beverage consumption was higher in younger age groups $(P<0.001)$, those in lower socio-economic categories $(P<0 \cdot 001)$, those born in Australia $(P<0 \cdot 001)$, those with higher BMI $(P<0.001)$ and those with lower fruit $(P<0.001)$ or vegetable intake $(P<0.001)$. Discretionary beverage consumption $(\beta=6.6, P<0.001)$ was more strongly associated with BMI than discretionary food consumption $(\beta=0.5$, $P=0 \cdot 01)$.

Conclusions: Total discretionary food/beverage consumption as well as discretionary foods alone and discretionary beverages alone were associated with BMI in Australian adults. In addition, high intakes were associated with younger age, lower socio-economic status, and lower consumption of fruit and vegetables.
\end{abstract}



Obesity and central obesity ${ }^{(1)}$ are independent risk factors for various adverse health outcomes, including certain cancers, diabetes and $\mathrm{CVD}^{(2-4)}$. The latest Australian Health Survey (2011-12) found that nearly two-thirds of Australian adults were overweight or obese (70\% of males and $56 \%$ of females), with a rising trend over the past decades $^{(5)}$.

Discretionary foods and beverages are usually high in saturated fat, sugar or salt, and low in fibre and micronutrients, and should be consumed 'only sometimes and in small amounts ${ }^{\prime(6)}$ according to the Australian Dietary Guidelines $^{(7)}$. Long-term consumption of these energydense and nutrient-poor foods and beverages might facilitate positive energy imbalance and result in weight gain $^{(8,9)}$. Extensive studies have demonstrated that energy consumed in both liquid and solid form independently increases the risk of obesity ${ }^{(10-12)}$. Additionally, studies have shown that energy consumed in liquid form is more obesogenic than when consumed in solid form ${ }^{(11,13,14)}$.

Excessive consumption of discretionary foods/ beverages in the Australian population has been identified in national dietary surveys undertaken since 1995, comprising $40 \%$ of daily energy intake in $1995^{(15)}, 41 \%$ in children in $2007^{(16)}$ and $35 \%$ in $2011 / 12^{(5)}$.

The recent release of data from the 2011-12 National Nutrition and Physical Activity Survey (NNPAS) enables 
the assessment of factors associated with the consumption of discretionary foods/beverages such as demographic, anthropometric and dietary factors. The aim of the current study was to examine the association between these factors and the consumption of discretionary foods, discretionary beverages and discretionary foods/ beverages combined. Findings will assist in identifying sub-populations that would benefit most from being targeted in public health campaigns.

\section{Methods}

\section{Respondents and dietary data collection}

The present study utilized data from the 2011-12 NNPAS, undertaken by the Australian Bureau of Statistics to collect nutrition and health information of the Australian population. The 2011-12 NNPAS was conducted between May 2011 and June 2012 in adults and children aged 2 years or over. Ethics approval for the survey was granted by the Australian Government Department of Health and Ageing Departmental Ethics Committee in 2011. Further details about the scope and methodology of the survey are available from the NNPAS user's guide published by the Australian Bureau of Statistics ${ }^{(17)}$. A total of 12154 respondents aged 2 years or over were interviewed face-to-face for the collection of dietary intake data using a $24 \mathrm{~h}$ recall and a second $24 \mathrm{~h}$ recall was collected from 7735 respondents via a telephone interview.

\section{Categorization of discretionary foods/beverages}

In the present study, discretionary foods/beverages recorded in the $24 \mathrm{~h}$ recalls were defined and provided by the Australian Bureau of Statistics in line with the Australian Dietary Guidelines' description of 'foods high in saturated fat and/or added sugars, added salt or alcohol and low in fibre ${ }^{(5)}$. Discretionary foods (solid) included foods such as cakes, biscuits, pastries, deep-fried fast foods, processed meat, crisps, butter, cream, ice cream, chocolate, confectionery, jam and sweet spreads. Discretionary beverages (liquid) included alcoholic (e.g. wine, beer, spirits) and non-alcoholic beverages (e.g. soft drinks, fruit drinks, energy drinks, sports drinks). Discretionary foods/beverages combined both foods and beverages.

\section{Anthropometry and demographic characteristics}

Respondents' weight, height and waist circumference (WC) were objectively measured in the NNPAS. Interviewers used digital scales to measure weight, a stadiometer to measure height and a metal tape measure (which avoided the risk of the tape stretching) to measure $\mathrm{WC}^{(17)}$. Using the measured weight and height, BMI was calculated to categorize respondents into different weight categories (underweight, BMI $<18.5 \mathrm{~kg} / \mathrm{m}^{2}$; normal weight, BMI $=18.5-24.9 \mathrm{~kg} / \mathrm{m}^{2}$; overweight, BMI $=25.0$ $29.9 \mathrm{~kg} / \mathrm{m}^{2}$; obesity, BMI $\left.\geq 30.0 \mathrm{~kg} / \mathrm{m}^{2(1)}\right)$. Respondents were also classified into different central obesity categories according to WC cut-off ranges (not at risk, WC $<94 \mathrm{~cm}$ (men) and $\mathrm{WC}<80 \mathrm{~cm}$ (women); at risk, $\mathrm{WC} \geq 94 \mathrm{~cm}$ (men) and $\mathrm{WC} \geq 80 \mathrm{~cm}$ (women); centrally obese, $W C \geq 102 \mathrm{~cm}$ (men) and $W C \geq 88 \mathrm{~cm}$ (women) ${ }^{(1)}$ ). In the present study, data obtained from 7873 adults (19 years or above) with at least one $24 \mathrm{~h}$ dietary recall and weight and height measured were used for analyses, with the results weighted to reflect the Australian population ${ }^{(5-7)}$.

Age groups were based on the NNPAS age categories (19-30, 31-50, 51-70 and 70+ years) and socio-economic quintiles were based on the Socio-Economic Index of Disadvantage for Areas (SEIFA), where the first SEIFA quintile indicates the most disadvantaged areas ${ }^{(5)}$. Country of birth was classified according to whether the respondents were born in Australia, English-speaking countries, or others.

\section{Fruit and vegetable consumption}

The term 'fruit(s)' as used herein refers to fresh, frozen, canned and dried fruit, and fruit juice with no added sugar, as described in the Australian Guide to Healthy Eating ${ }^{(6)}$. The term 'vegetable(s)' refers to non-starchy dark green or cruciferous vegetables, root/tubular/bulb vegetables, legumes/beans and other vegetables (e.g. avocado and mushrooms $)^{(6)}$. Starchy vegetables were not included in the analysis as they are less nutrient dense and higher in energy than other vegetables ${ }^{(7)}$ and have been associated with weight gain in previous studies ${ }^{(18)}$. Fruit and vegetable consumption from all sources was estimated from both the individually recorded food items (e.g. banana consumed as a snack) and mixed dishes (e.g. vegetables in a stir-fry). The fruit and vegetable components of a mixed dish were estimated using the AUSNUT 2011-13 recipe file ${ }^{(19)}$. For example, the proportion of vegetables in a stir-fry was determined from the recipe file and translated into grams of vegetables consumed. The numbers of servings of fruits ( 1 standard serving is $150 \mathrm{~g}$ ) and vegetables (1 standard serving is $75 \mathrm{~g}$ ) were determined for each respondent. Fruit consumption was further categorized as non-consumer, $<1$ serving/d, 1-2 servings/d and $>2$ servings/d. Vegetable consumption was further categorized into non-consumer, $<2.5$ servings/d, 2.5-5 servings/d and $>5$ servings/d.

\section{Misreporting}

Misreporting has been identified in the 2011-12 NNPAS survey, with $16-26 \%$ of adult respondents classified as under-reporting total energy intake ${ }^{(5)}$. To enable a more accurate interpretation of dietary data especially when examining associations with BMI, it has been suggested that potential under- and over-reporters be removed from the analysis ${ }^{(20-22)}$. Plausible reporters were identified based on the Goldberg cut-off (ratio of energy intake to BMR $=0.92-2 \cdot 17)^{(23)}$. The Goldberg cut-offs have been validated for use with data from $24 \mathrm{~h}$ recalls ${ }^{(24)}$. In the 
current paper only the results from plausible reporters are presented ( $n$ 5361), while the results from all reporters (including potential under-reporters $n$ 2470, overreporters $n 42$ ) are presented in the online supplementary material, Supplemental Tables 1 and 2 .

\section{Statistical analysis}

Statistical analyses were performed using the statistical software package IBM SPSS Statistics for Windows Version 22.0. Respondents' usual intakes of total energy, discretionary foods/beverages, fruits and vegetables using data from the two $24 \mathrm{~h}$ recalls were analysed using the Multiple Source Method ${ }^{(25)}$. Descriptive statistics were used to report the proportions of respondents and the mean consumption of discretionary foods/beverages according to different characteristics. The $\chi^{2}$ test and ANOVA were used to assess differences between proportions and to compare mean differences in consumption where appropriate. Separate multivariate regression analyses were undertaken to investigate the factors associated with discretionary food/beverage consumption, discretionary food consumption and discretionary beverage consumption. The continuous explanatory variables including age, BMI, WC, fruit and vegetable intakes, and categorical variables including gender, SEIFA and country of birth, were all entered into the model simultaneously to determine which factors were independently associated with discretionary foods and beverages. The $\beta$ coefficient was interpreted as the change in the weight of food consumption per category change of the explanatory variable, holding the other variables constant. Data transformations were not used to correct for any departures from normality, as the sample size was sufficiently large for the central limit theorem to apply ${ }^{(26)}$. For all tests, a $P$ value of $<0 \cdot 05$ was considered statically significant.

\section{Results}

The vast majority of respondents reported consuming discretionary foods/beverages on the day surveyed (98.3\%). The mean discretionary food/beverage consumption was $630.6 \mathrm{~g}(27.9 \%$ by weight from foods; $72.1 \%$ from beverages), providing $2721 \mathrm{~kJ}$ of energy $(72 \cdot 2 \%$ from foods; $27 \cdot 8 \%$ from beverages) which accounted for $34.5 \%$ of total daily energy intake. Differences in the reporting of discretionary food/beverage consumption within the demographic, anthropometric and dietary categories are shown in Table 1.

\section{Discretionary foods (solid) v. discretionary beverages (liquid)}

The proportion of the population reporting consumption of discretionary foods (solid) was significantly higher than that reporting consumption of discretionary beverages (liquid) $(P<0.01)$. The proportion consuming discretionary foods (solid) was similar for males and females, between age groups, SEIFA quintiles, BMI groups, and fruit and vegetable categories, while an increase was noted with higher WC categories and among those who were born in Australia. The proportion of adults consuming discretionary beverages (liquid) was significantly lower in females, older age groups, those born in non-English speaking countries and for those with greater fruit and vegetable intakes, but was higher for those in higher BMI and WC categories.

The mean intakes of discretionary foods/beverages were significantly greater for males than females, and were higher in the younger age groups, for those in the lower SEIFA categories, those born in Australia, those with higher BMI, and those with lower fruit and vegetable intakes.

\section{Percentage contribution to energy}

The contribution of discretionary foods/beverages to daily energy intake by demographic, anthropometric and dietary characteristics is shown in Fig. 1, with a total energy contribution of $34.5 \%$. Discretionary foods (solid) comprised a larger proportion of total energy intake (24.6\%) than discretionary beverages (liquid) (9.9\%). A larger proportion of energy derived from discretionary foods/beverages was reported by males, lower SEIFA quintiles, higher BMI and WC categories, and lower fruit and vegetable categories. In particular, those who reported consuming $<2.5$ servings of vegetables on the survey day obtained $36.7 \%$ of their energy intake from discretionary foods/beverages, followed by those who reported consuming $<1$ serving of fruit $(36 \cdot 4 \%)$.

\section{Multivariate analysis}

The multivariate analyses examining the association between change in discretionary food/beverage consumption and respondents' characteristics are shown in Table 2. Gender, age, SEIFA, birth in non-English speaking countries, BMI, and fruit and vegetable intakes were all significantly and independently associated with the amount of discretionary foods/beverages consumed, but not WC. In sub-analyses separating discretionary foods and beverages, SEIFA, birth in non-English speaking countries, BMI, and fruit and vegetable intakes were significantly associated with higher discretionary food (solid) intake, not gender or age. The association between BMI and discretionary foods/beverages was not significant for analyses using all respondents including potential under- and over-reporters (see online supplementary material, Supplemental Tables 1 and 2 for details).

\section{Discussion}

The current analysis of the most recent Australian national representative survey shows that most Australian adults consumed large amounts of discretionary foods/beverages 
Table 1 Consumption of discretionary foods/beverages by demographic, anthropometric and dietary characteristics among Australian adults ( $n$ 5361; plausible reporters only) aged 19 years or above participating in the 2011-12 National Nutrition and Physical Activity Survey

\begin{tabular}{|c|c|c|c|c|c|c|c|c|c|c|}
\hline \multirow[b]{3}{*}{ Characteristic/category } & \multirow{3}{*}{$\begin{array}{l}\text { Proportion of } \\
\text { population (\%) }\end{array}$} & \multicolumn{3}{|c|}{ Discretionary foods/beverages } & \multicolumn{3}{|c|}{ Discretionary foods (solid) } & \multicolumn{3}{|c|}{ Discretionary beverages (liquid) } \\
\hline & & \multirow{2}{*}{$\begin{array}{l}\text { Proportion of } \\
\text { consumers (\%) }\end{array}$} & \multicolumn{2}{|c|}{ Per capita consumption (g) } & \multirow{2}{*}{$\begin{array}{c}\text { Proportion of } \\
\text { consumers (\%) }\end{array}$} & \multicolumn{2}{|c|}{ Per capita consumption (g) } & \multirow{2}{*}{$\begin{array}{l}\text { Proportion of } \\
\text { consumers (\%) }\end{array}$} & \multicolumn{2}{|c|}{ Per capita consumption $(\mathrm{g})$} \\
\hline & & & Mean & SD & & Mean & SD & & Mean & SD \\
\hline \multicolumn{11}{|l|}{ Gender } \\
\hline Male & $48 \cdot 3$ & $98.4 \dagger \dagger$ & $729 \cdot 5^{\star \star}$ & 541.0 & 95.6 & $181 \cdot 6^{\star *}$ & $86 \cdot 7$ & 74.3†† & $547 \cdot 9^{\star *}$ & $467 \cdot 2$ \\
\hline Female & $51 \cdot 7$ & 98.2 & $476 \cdot 6$ & 340.6 & $96 \cdot 0$ & 153.5 & $70 \cdot 8$ & 61.7 & $323 \cdot 1$ & 263 \\
\hline \multicolumn{11}{|l|}{ Age (years) } \\
\hline $19-30$ & $17 \cdot 6$ & $98.3+\dagger$ & $666 \cdot 7^{\star *}$ & 518.5 & $96 \cdot 0$ & $181 \cdot 8^{\star \star}$ & 89.8 & $71.4 \dagger \dagger$ & $484 \cdot 9^{* *}$ & $415 \cdot 8$ \\
\hline $31-50$ & 38.3 & 98.5 & 629.2 & 487.8 & $96 \cdot 2$ & 170.5 & 81.2 & $69 \cdot 0$ & $458 \cdot 7$ & 397.9 \\
\hline $51-70$ & $30 \cdot 3$ & 98.0 & 593.6 & 464.1 & 94.7 & 159.2 & $75 \cdot 4$ & 68.8 & 434.4 & 408.4 \\
\hline \multirow{2}{*}{\multicolumn{11}{|c|}{ SEIFA quintile }} \\
\hline & & & & & & & & & & \\
\hline 1st (lowest) & $17 \cdot 3$ & 97.9 & $637 \cdot 2^{\star \star}$ & 523.4 & $95 \cdot 3$ & $172 \cdot 9^{\star \star}$ & 82.6 & $67 \cdot 3$ & $464 \cdot 2^{\star \star}$ & 434.4 \\
\hline 2nd & $20 \cdot 1$ & 98.1 & $626 \cdot 0$ & 508.4 & 95.3 & $172 \cdot 2$ & 82.0 & 68.3 & $453 \cdot 7$ & $413 \cdot 6$ \\
\hline $3 r d$ & $20 \cdot 9$ & 98.8 & 595.7 & 468.6 & $96 \cdot 3$ & $169 \cdot 0$ & $80 \cdot 9$ & $67 \cdot 1$ & 426.7 & 397.8 \\
\hline 4th & $17 \cdot 3$ & $98 \cdot 1$ & $569 \cdot 1$ & $404 \cdot 0$ & 95.7 & $167 \cdot 3$ & 83.8 & $66 \cdot 9$ & 401.8 & 331.6 \\
\hline 5th (highest) & 24.5 & 98.4 & 573.1 & 439.6 & $96 \cdot 2$ & 157.0 & $72 \cdot 2$ & 68.8 & $416 \cdot 1$ & 375.1 \\
\hline \multicolumn{11}{|l|}{ Country of birth } \\
\hline Australia & $70 \cdot 7$ & $99.0 \dagger$ & $634 \cdot 2^{\star \star}$ & $482 \cdot 9$ & $97.0 \ddagger$ & $171 \cdot 9^{\star \star}$ & $80 \cdot 4$ & $70 \cdot 1 \dagger$ & $462 \cdot 3^{\star \star}$ & 411.4 \\
\hline English-speaking countries & $12 \cdot 9$ & 98.3 & 601.3 & $487 \cdot 7$ & 96.0 & $169 \cdot 0$ & 79.5 & $69 \cdot 6$ & $432 \cdot 3$ & $382 \cdot 8$ \\
\hline Others & $16 \cdot 4$ & $96 \cdot 7$ & 444.2 & 348.6 & 93.6 & 144.9 & $75 \cdot 8$ & 53.6 & 299.4 & $267 \cdot 8$ \\
\hline \multicolumn{11}{|l|}{ BMl category } \\
\hline Underweight & 1.8 & $98.9 \dagger$ & $585 \cdot 8^{*}$ & 534.5 & $96 \cdot 8$ & $171 \cdot 8^{*}$ & 79.6 & $65.3 \dagger$ & $414 \cdot 0^{* *}$ & 428.3 \\
\hline Normal & 39.4 & 98.8 & $543 \cdot 8$ & 435.4 & $96 \cdot 2$ & $160 \cdot 7$ & 78.1 & $64 \cdot 2$ & $383 \cdot 1$ & 351.9 \\
\hline Overweight & 37.4 & 98.8 & 626.9 & 471.6 & $96 \cdot 2$ & $169 \cdot 6$ & $82 \cdot 1$ & $70 \cdot 0$ & 457.4 & $404 \cdot 8$ \\
\hline Obesity & 21.4 & 98.8 & 652.1 & 509.8 & 96.6 & 174.1 & 79.5 & 71.3 & 478.1 & $426 \cdot 4$ \\
\hline \multicolumn{11}{|l|}{ WC category } \\
\hline Not at risk & $38 \cdot 2$ & $96 \cdot 0 \dagger \dagger$ & $575 \cdot 7^{\star}$ & $460 \cdot 7$ & $93.3 \dagger$ & $165 \cdot 5^{\star}$ & $80 \cdot 3$ & $63.7 \dagger \dagger$ & $410 \cdot 2^{*}$ & $367 \cdot 1$ \\
\hline At risk & 23.4 & 95.5 & 607.6 & $466 \cdot 7$ & 93.3 & $168 \cdot 2$ & $79 \cdot 3$ & 67.6 & 439.4 & 389.4 \\
\hline Central obesity & $36 \cdot 5$ & $98 \cdot 3$ & 617.8 & 479 & $96 \cdot 0$ & 168.2 & 80.2 & 69.4 & 449.6 & $416 \cdot 8$ \\
\hline \multicolumn{11}{|l|}{ Fruit consumption } \\
\hline$<1$ serving & $41 \cdot 3$ & $98.8 \dagger \dagger$ & $673 \cdot 0^{\star \star}$ & 531.8 & $96 \cdot 3$ & $176 \cdot 3^{\star}$ & 83.0 & $67.5 \dagger \dagger$ & $496 \cdot 7^{\star \star}$ & 444.7 \\
\hline $1-2$ servings & $43 \cdot 8$ & 98.0 & $563 \cdot 2$ & $422 \cdot 3$ & 95.6 & 163.0 & 77.5 & 63.9 & $400 \cdot 2$ & 361.0 \\
\hline$>2$ servings & 14.9 & 97.1 & $498 \cdot 2$ & 345.6 & 94.7 & 153.7 & $76 \cdot 7$ & 58.7 & 344.5 & 282.1 \\
\hline \multicolumn{11}{|l|}{ Vegetable consumption } \\
\hline$<2.5$ servings & 34.9 & $99.2 \dagger \dagger$ & $623 \cdot 4^{* *}$ & $469 \cdot 7$ & $96 \cdot 6$ & $166 \cdot 3^{*}$ & $75 \cdot 6$ & $70 \cdot 8 \dagger \dagger$ & $457 \cdot 1^{\star *}$ & $417 \cdot 7$ \\
\hline $2.5-5$ servings & $59 \cdot 1$ & $97 \cdot 3$ & $591 \cdot 1$ & $465 \cdot 2$ & 95.4 & $167 \cdot 1$ & $80 \cdot 2$ & $65 \cdot 8$ & 424.0 & $377 \cdot 7$ \\
\hline$>5$ servings & $6 \cdot 0$ & $96 \cdot 3$ & 531.5 & $528 \cdot 1$ & $92 \cdot 8$ & 171.4 & $102 \cdot 2$ & $56 \cdot 9$ & $360 \cdot 2$ & 367.9 \\
\hline
\end{tabular}

SEIFA, Socio-Economic Index of Disadvantage for Areas; WC, waist circumference.

Mean value was significantly different by characteristic category (ANOVA): ${ }^{*} P<0.05,{ }^{*} P<0.01$.
Proportion of consumers was significantly different by characteristic category $\left(\chi^{2}\right.$ analysis): $\dagger P<0.05, \dagger \dagger P<0.01$. 


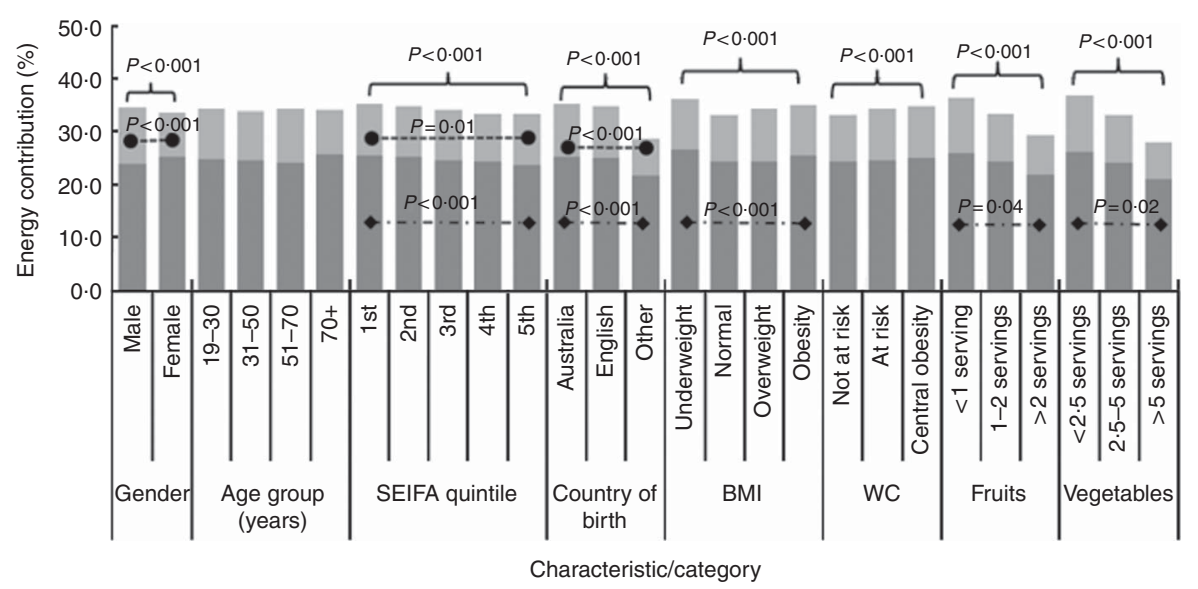

Fig. 1 Contribution (\%) of discretionary foods/beverages to energy intake by demographic, anthropometric and dietary characteristics among Australian adults ( $n$ 5361; plausible reporters only) aged 19 years or above participating in the 2011-12 National Nutrition and Physical Activity Survey ( $\square$, discretionary foods; $\square$, discretionary beverages; $\bullet-\cdots$, significant difference (discretionary foods); $\bullet . . . \cdot \bullet$, significant difference (discretionary beverages)). (SEIFA, Socio-Economic Index of Disadvantage for Areas (1st quintile = lowest, 5th quintile = highest); Country of birth, 'English' = English-speaking countries; WC, waist circumference)

on the day surveyed, amounting to $34.5 \%$ of total energy intake. More people reported consuming discretionary foods than discretionary beverages, which also comprised a larger proportion of total energy intake. Discretionary food/beverage consumption differed across subpopulations, with higher consumption levels among males, younger people, people of lower socio-economic status, people with high BMI, and people with low fruit and vegetable intakes.

Compared with previous studies examining discretionary choices using the 1995 National Nutrition Survey, which contributed $36 \%$ of total energy ${ }^{(15)}$, our results suggest that discretionary food/beverage consumption appears to have plateaued. However, the two studies are not directly comparable, as there were slight differences in the criteria for discretionary foods/beverages. Consistent with the 1995 findings ${ }^{(15)}$, discretionary foods, which are relatively more energy dense than beverages, comprised a larger amount of total energy intake than discretionary beverages, despite the much smaller consumption.

Our findings are consistent with results from national surveys across the world. The National Health and Nutrition Examination Survey of the USA, although adopting a different approach for food grouping, reported that energy-dense and nutrient-poor foods/beverages comprised at least $36 \%$ of the total energy intake of US adults $^{(27)}$. The National Diet and Nutrition Survey of the UK did not provide separate analysis for discretionary foods/beverages but did recognize the large and constant contribution of food intakes from unhealthy choices including hot chips, processed meat, confectionery and soft drinks among adults from 2000 to $2009^{(28)}$. The Brazilian National Dietary Survey also found that desserts, sugar-sweetened beverages, soft drinks, processed meats and savoury snacks together were the greatest source of energy for people aged 10 years or older ${ }^{(29)}$.
Our findings confirm that age and gender are important determinants of the quantity of discretionary foods/beverages consumed ${ }^{(15)}$. We also observed higher discretionary food/beverage consumption by people of lower socio-economic groups (represented by lower SEIFA category), those born in Australia and English-speaking countries, and those with lower fruit and vegetable intakes. These characteristics parallel the sociodemographic features of the overweight and obese population in Australia ${ }^{(30)}$ and suggest that discretionary food/beverage consumption is an important contributor to the obesity epidemic. Previous Australian studies have identified that exposure to energy-dense snack foods and soft drinks was greater in socio-economically disadvantaged neighbourhoods ${ }^{(31)}$. The wide range, easy access and relatively low cost make these products an attractive option for many people $e^{(32,33)}$.

We found a positive association between consumption of discretionary foods/beverages and BMI, as well as between consumption of discretionary foods or beverages alone and BMI. Discretionary beverages, however, showed a stronger association with BMI than discretionary foods. Consistent evidence suggests that energycontaining beverages are more strongly associated with obesity compared with solid foods ${ }^{(13,14,34)}$. One explanation may be the comparably rapid ingestion rate of liquid, which leads to a weaker physiological sensory response than for solid food ${ }^{(35)}$. Hence, consumption of discretionary beverages results in lower satiety than consumption of foods ${ }^{(36-39)}$, leading to overconsumption ${ }^{(35)}$ and substantial increases in energy intake $\mathrm{e}^{(11,40,41)}$.

Higher fruit and vegetable intakes were independently associated with lower discretionary food/beverage consumption. Respondents who consumed more than two servings of fruit $(300 \mathrm{~g}$ ) also consumed $23.2 \mathrm{~g}$ less discretionary foods and $128.8 \mathrm{~g}$ less discretionary beverages than 
Table 2 Associations of discretionary food/beverage consumption (g) with demographic, anthropometric and dietary characteristics among Australian adults ( $n$ 5361; plausible reporters only) aged 19 years or above participating in the 2011-12 National Nutrition and Physical Activity Survey

\begin{tabular}{|c|c|c|c|c|}
\hline & $B$ & SE & $\beta$ & $P$ value \\
\hline \multicolumn{5}{|l|}{ Discretionary foods/beverages $(\mathrm{g})$} \\
\hline Gender (Male) & $82 \cdot 2$ & 13.6 & 0.09 & $<0.001$ \\
\hline Age (year) & $-2 \cdot 2$ & 0.4 & -0.08 & $<0.001$ \\
\hline \multicolumn{5}{|l|}{ SEIFA (ref. $=1$ st quintile) } \\
\hline 2nd quintile & -12.9 & $17 \cdot 6$ & -0.01 & 0.47 \\
\hline 3rd quintile & -53.4 & 17.5 & -0.05 & 0.002 \\
\hline 4th quintile & $-95 \cdot 8$ & $18 \cdot 3$ & -0.08 & $<0.001$ \\
\hline 5th quintile & $-51 \cdot 4$ & $17 \cdot 0$ & -0.05 & 0.003 \\
\hline \multicolumn{5}{|l|}{ Country of birth (ref. = Australia) } \\
\hline English-speaking countries & -0.2 & $16 \cdot 4$ & 0.00 & 0.99 \\
\hline Others & -174.0 & 14.9 & -0.14 & $<0.001$ \\
\hline BMI $\left(\mathrm{kg} / \mathrm{m}^{2}\right)$ & 6.6 & $2 \cdot 1$ & 0.17 & 0.002 \\
\hline WC $(\mathrm{cm})$ & 5.4 & $0 \cdot 8$ & 0.06 & 0.48 \\
\hline Fruit consumption (per serving) & $-120 \cdot 1$ & 7.4 & -0.19 & $<0.001$ \\
\hline Vegetable consumption (per serving) & $-52 \cdot 3$ & 4.7 & -0.13 & $<0.001$ \\
\hline \multicolumn{5}{|l|}{ Discretionary foods (solid) (g) } \\
\hline Gender (Male) & 0.6 & 2.5 & 0.00 & 0.79 \\
\hline Age (years) & 0.0 & 0.1 & 0.00 & 0.80 \\
\hline \multicolumn{5}{|l|}{ SEIFA (ref. =1st quintile) } \\
\hline 2nd quintile & $-2 \cdot 2$ & $3 \cdot 3$ & -0.01 & 0.49 \\
\hline 3rd quintile & $-6 \cdot 9$ & $3 \cdot 2$ & -0.04 & 0.03 \\
\hline 4th quintile & -7.9 & 3.4 & -0.04 & 0.02 \\
\hline 5th quintile & -13.6 & $3 \cdot 1$ & -0.07 & $<0.001$ \\
\hline \multicolumn{5}{|l|}{ Country of birth (ref. = Australia) } \\
\hline English-speaking countries & $-0 \cdot 6$ & $3 \cdot 0$ & 0.00 & 0.85 \\
\hline Others & $-22 \cdot 2$ & $2 \cdot 7$ & -0.10 & $<0.001$ \\
\hline BMI $\left(\mathrm{kg} / \mathrm{m}^{2}\right)$ & 0.5 & 0.4 & 0.03 & 0.01 \\
\hline WC $(\mathrm{cm})$ & -0.1 & 0.2 & -0.02 & 0.35 \\
\hline Fruit consumption (per serving) & -11.6 & 1.4 & -0.11 & $<0.001$ \\
\hline Vegetable consumption (per serving) & -5.5 & 0.9 & -0.08 & $<0.001$ \\
\hline \multicolumn{5}{|l|}{ Discretionary beverages (liquid) (g) } \\
\hline Gender (Male) & $123 \cdot 8$ & $12 \cdot 4$ & 0.16 & $<0.001$ \\
\hline Age (years) & $-2 \cdot 6$ & 0.3 & -0.12 & $<0.001$ \\
\hline \multicolumn{5}{|l|}{ SEIFA (ref. $=1$ st quintile) } \\
\hline 2nd quintile & -11.4 & $16 \cdot 1$ & -0.01 & 0.48 \\
\hline 3rd quintile & $-37 \cdot 3$ & $15 \cdot 9$ & -0.04 & 0.02 \\
\hline 4th quintile & $-66 \cdot 4$ & $16 \cdot 7$ & -0.06 & $<0.001$ \\
\hline 5th quintile & -23.8 & $15 \cdot 5$ & -0.03 & 0.01 \\
\hline \multicolumn{5}{|l|}{ Country of birth (ref. $=$ Australia) } \\
\hline English-speaking countries & $-10 \cdot 1$ & $14 \cdot 9$ & -0.01 & 0.50 \\
\hline Others & -137.7 & 13.6 & -0.13 & $<0.001$ \\
\hline BMI $\left(\mathrm{kg} / \mathrm{m}^{2}\right)$ & $6 \cdot 6$ & 1.9 & 0.08 & 0.001 \\
\hline WC $(\mathrm{cm})$ & 5.4 & 0.8 & 0.19 & $<0.001$ \\
\hline Fruit consumption (per serving) & -64.4 & $6 \cdot 7$ & -0.12 & $<0.001$ \\
\hline Vegetable consumption (per serving) & $-40 \cdot 3$ & 4.3 & -0.12 & $<0.001$ \\
\hline
\end{tabular}

those who did not report any fruit consumption. Respondents who had more than five servings of vegetables $(375 \mathrm{~g})$ consumed $27.5 \mathrm{~g}$ less discretionary foods and $201.5 \mathrm{~g}$ less discretionary beverages than those who did not report any vegetable consumption. Similarly, a previous study by Cohen et al. also found that despite the statistically significant inverse association between discretionary food consumption and fruit and vegetable consumption in the US population, the magnitude of change was small ${ }^{(8)}$. However, in terms of energy contribution, respondents who consumed more than two servings of fruits or five servings of vegetables had significantly a lower percentage of energy from discretionary foods/beverages than those who did not report any fruit or vegetable consumption. The large difference in energy density between fruits/vegetables and discretionary foods/ beverages indicates that fruits and non-starchy vegetables may play an important role in the public health effort to reduce energy intake. The finding is partially confirmed by observations from the Brazilian National Dietary Survey that found non-starchy vegetables was the only food group inversely associated with total energy intake ${ }^{(29)}$.

Previous evidence about total discretionary food/beverage consumption was based on data mainly from large national nutrition surveys, from which the associations identified were likely to be conservative due to the high levels of energy misreporting ${ }^{(20,21,42)}$. Many studies have associated under-reporting with age, gender, BMI and 
socio-economic status ${ }^{(21,22,43,44)}$. Under-reporting of energy intake is also likely to be biased towards particular foods, with the Australian Bureau of Statistics ${ }^{(17)}$ stating that: 'Given the association of under-reporting with overweight/obesity and consciousness of socially acceptable/desirable dietary patterns, discretionary foods would be expected to be more likely to be under-reported than non-discretionary foods.' Exclusion of misreporters has been recommended when examining associations between BMI and other variables. This was again confirmed in our study, with significant associations observed between BMI and discretionary foods/beverages only after excluding misreporters. A more detailed investigation is required to compare the types of foods most likely to be misreported.

The strength of the present study included the use of a large representative sample of the Australian population. All fruit and vegetable intake was accounted for as all mixed dishes were disaggregated. Furthermore, anthropometric measures were objectively measured which excludes the possibility of reporting bias. The present study also has several limitations. First, our results are from cross-sectional data and causal relationships cannot be inferred. In addition, although it is desirable to spread the dietary recalls across all days of the week, data about Saturday food intake were significantly under-represented in the NNPAS; this might result an underestimation of discretionary food/beverage consumption considering that eating behaviours during weekends might be different from those on weekdays.

\section{Conclusion}

In conclusion, our findings showed that total discretionary food and beverage consumption was associated with younger age, higher BMI, lower socio-economic status and low consumption of fruits and vegetables. Our analysis supports the current national guidelines to limit the consumption of discretionary foods/beverages.

\section{Acknowledgements}

Acknowledgements: The authors thank the Australian Bureau of Statistics for permission to use the 2011-12 NNPAS data. Financial support: This research received no specific grant from any funding agency in the public, commercial or not-for-profit sectors. Conflict of interest: The authors declare that there are no conflicts of interest. Authorship: Z.S. and W.K.W. were responsible for data analysis, and together with A.R. and J.C.Y.L. interpreted the data and wrote the manuscript. Ethics of buman subject participation: Ethics approval for the NNPAS was granted by the Australian Government Department of Health and Ageing Departmental Ethics Committee in 2011. Ethics approval was not required for the current secondary data analysis.

\section{Supplementary material}

To view supplementary material for this article, please visit http://dx.doi.org/10.1017/S1368980016002305

\section{References}

1. Australian Government, Australian Institute of Health and Welfare (2015) Overweight and obesity. http://www.aihw. gov.au/overweight-and-obesity/ (accessed July 2016).

2. Birks S, Peeters A, Backholer K et al. (2012) A systematic review of the impact of weight loss on cancer incidence and mortality. Obes Rev 13, 868-891.

3. Mokdad AH, Bowman BA, Ford ES et al. (2001) The continuing epidemics of obesity and diabetes in the United States. JAMA 286, 1195-1200.

4. Shahraki M, Shahraki T, Pourghasem Gargari B et al. (2012) Central obesity and coronary heart disease risk factors in referral outpatients to Zahedan Cardiology Clinic, Iran. Int J High Risk Behav Addict 1, 79-83.

5. Australian Bureau of Statistics (2014) Australian Health Survey: Nutrition First Results - Foods and Nutrients, 2011-12. Canberra: ABS.

6. National Health and Medical Research Council (2013) Australian Guide to Healthy Eating. Canberra: NHMRC.

7. National Health and Medical Research Council (2013) Australian Dietary Guidelines. Canberra: NHMRC.

8. Cohen DA, Sturm R, Scott M et al. (2010) Not enough fruit and vegetables or too many cookies, candies, salty snacks, and soft drinks? Public Health Rep 125, 88-95.

9. Millar L, Rowland B, Nichols M et al. (2014) Relationship between raised BMI and sugar sweetened beverage and high fat food consumption among children. Obesity (Silver Spring) 22, E96-E103.

10. Aston LM, Smith JN \& Powles JW (2013) Meat intake in Britain in relation to other dietary components and to demographic and risk factor variables: analyses based on the National Diet and Nutrition Survey of 2000/2001. J Hum Nutr Diet 26, 96-106.

11. Zheng M, Allman-Farinelli M, Heitmann BL et al. (2015) Liquid versus solid energy intake in relation to body composition among Australian children. J Hum Nutr Diet 28, Suppl. 2, 70-79.

12. Togo P, Osler M, Sorensen TI et al. (2001) Food intake patterns and body mass index in observational studies. Int $J$ Obes Relat Metab Disord 25, 1741-1751.

13. DiMeglio DP \& Mattes RD (2000) Liquid versus solid carbohydrate: effects on food intake and body weight. Int $J$ Obes Relat Metab Disord 24, 794-800.

14. Houchins JA, Burgess JR, Campbell WW et al. (2012) Beverage vs. solid fruits and vegetables: effects on energy intake and body weight. Obesity (Silver Spring) 20, 1844-1850.

15. Rangan AM, Schindeler S, Hector DJ et al. (2009) Consumption of 'extra' foods by Australian adults: types, quantities and contribution to energy and nutrient intakes. Eur J Clin Nutr 63, 865-871.

16. Rangan AM, Randall D, Hector DJ et al. (2008) Consumption of 'extra' foods by Australian children: types, quantities and contribution to energy and nutrient intakes. Eur J Clin Nutr 62, 356-364.

17. Australian Bureau of Statistics (2013) Australian Health Survey: User's Guide, 2011-13. Canberra: ABS.

18. Mozaffarian D, Hao T, Rimm EB et al. (2011) Changes in diet and lifestyle and long-term weight gain in women and men. N Engl J Med 364, 2392-2404.

19. Food Standards Australia New Zealand (2014) Australian Food, Supplement and Nutrient Database (AUSNUT). Canberra: FSANZ. 
20. Rangan A, Allman-Farinelli M, Donohoe E et al. (2014) Misreporting of energy intake in the 2007 Australian Children's Survey: differences in the reporting of food types between plausible, under- and over-reporters of energy intake. J Hum Nutr Diet 27, 450-458.

21. Gemming L, Jiang Y, Swinburn B et al. (2014) Underreporting remains a key limitation of self-reported dietary intake: an analysis of the 2008/09 New Zealand Adult Nutrition Survey. Eur J Clin Nutr 68, 259-264.

22. Vanrullen IB, Volatier JL, Bertaut A et al. (2014) Characteristics of energy intake under-reporting in French adults. $\mathrm{Br} \mathrm{J}$ Nutr 111, 1292-1302.

23. Black AE (2000) The sensitivity and specificity of the Goldberg cut-off for EI:BMR for identifying diet reports of poor validity. Eur J Clin Nutr 54, 395-404.

24. Rennie KL, Coward A \& Jebb SA (2007) Estimating underreporting of energy intake in dietary surveys using an individualised method. Br J Nutr 97, 1169-1176.

25. Harttig U, Haubrock J, Knuppel S et al. (2011) The MSM program: web-based statistics package for estimating usual dietary intake using the Multiple Source Method. Eur J Clin Nutr 65, Suppl. 1, S87-S91.

26. Lumley T, Diehr P, Emerson S et al. (2002) The importance of the normality assumption in large public health data sets. Annu Rev Public Health 23, 151-169.

27. O'Neil CE, Keast DR, Fulgoni VL et al. (2012) Food sources of energy and nutrients among adults in the US: NHANES 2003-2006. Nutrients 4, 2097-2120.

28. Whitton C, Nicholson SK, Roberts C et al. (2011) National Diet and Nutrition Survey: UK food consumption and nutrient intakes from the first year of the rolling programme and comparisons with previous surveys. Br J Nutr 106, 1899-1914.

29. Sichieri R, Bezerra IN, Araujo MC et al. (2015) Major food sources contributing to energy intake - a nationwide survey of Brazilians aged 10 years and older. Br J Nutr $\mathbf{1 1 3}$, 1638-1642.

30. Taylor AW, Dal Grande E, Wu J et al. (2014) Ten-year trends in major lifestyle risk factors using an ongoing population surveillance system in Australia. Popul Health Metr 12, 31.

31. Cameron AJ, Thornton LE, McNaughton SA et al. (2013) Variation in supermarket exposure to energy-dense snack foods by socio-economic position. Public Health Nutr $\mathbf{1 6}$, $1178-1185$
32. Moubarac JC, Martins AP, Claro RM et al. (2013) Consumption of ultra-processed foods and likely impact on human health. Evidence from Canada. Public Health Nutr 16, 2240-2248.

33. Monteiro CA, Levy RB, Claro RM et al. (2011) Increasing consumption of ultra-processed foods and likely impact on human health: evidence from Brazil. Public Health Nutr 14 $5-13$.

34. Mattes RD (2006) Beverages and positive energy balance: the menace is the medium. Int J Obes (Lond) 30, S60-S65.

35. de Graaf C (2011) Why liquid energy results in overconsumption. Proc Nutr Soc 70, 162-170.

36. Houchins JA, Tan SY, Campbell WW et al. (2013) Effects of fruit and vegetable, consumed in solid vs beverage forms, on acute and chronic appetitive responses in lean and obese adults. Int J Obes (Lond) 37, 1109-1115.

37. Mattes RD (1996) Dietary compensation by humans for supplemental energy provided as ethanol or carbohydrate in fluids. Physiol Behav 59, 179-187.

38. Jones LV, Jones KM, Hensman C et al. (2013) Solid versus liquid-satiety study in well-adjusted lap-band patients. Obes Surg 23, 1266-1272.

39. Mattes RD \& Campbell WW (2009) Effects of food form and timing of ingestion on appetite and energy intake in lean young adults and in young adults with obesity. J Am Diet Assoc 109, 430-437.

40. Appelhans BM, Bleil ME, Waring ME et al. (2013) Beverages contribute extra calories to meals and daily energy intake in overweight and obese women. Physiol Behav 122, 129-133.

41. Mourao DM, Bressan J, Campbell WW et al. (2007) Effects of food form on appetite and energy intake in lean and obese young adults. Int J Obes (Lond) 31, 1688-1695.

42. Subar AF, Kipnis V, Troiano RP et al. (2003) Using intake biomarkers to evaluate the extent of dietary misreporting in a large sample of adults: the OPEN study. Am J Epidemiol 158, $1-13$

43. Bornhorst C, Huybrechts I, Ahrens W et al. (2013) Prevalence and determinants of misreporting among European children in proxy-reported $24 \mathrm{~h}$ dietary recalls. Br J Nutr 109, 1257-1265.

44. Kye S, Kwon SO, Lee SY et al. (2014) Under-reporting of energy intake from 24-hour dietary recalls in the Korean National Health and Nutrition Examination Survey. Osong Public Health Res Perspect 5, 85-91. 